\title{
Impact of Different Types of Voltage Sag on Adjustable Speed Drive
}

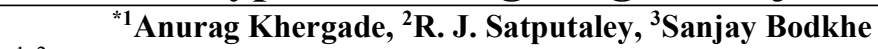

1,2 Visvesvaraya National Institute of Technology, Nagpur, India 440010

${ }^{3}$ Shri Ramdeobaba College of Engineering and Management, Nagpur, India 440013

Email:khergadeanurag@gmail.com,rsatputaley@gmail.com,bodkhesb@rknec.edu.

Received: 20th November 2019, Accepted: 31st January 2020, Published: 29th February 2020

\begin{abstract}
Modern industries are installed with an adjustable speed drive (ASD), which is more sensitive to power quality issues. The most common reason for the tripping of ASD is the voltage sag. Hence, the impact of various types of sags on the performance of ASD is presented in this paper. The basic topology of ASD fed by uncontrolled rectifier is presented in this paper. Different types of voltage sags occurred at point of common coupling with their causes are also discussed. To study the impact of voltage sag on ASD, a simulation is carried out using MATLAB software and the performance of ASD is tested under unsymmetrical voltage sag, symmetrical voltage sag and voltage sag with phase angle shift.
\end{abstract}

\section{Keywords}

Drive, Power Quality, Voltage Sag, Motor Torque and Speed.

\section{Introduction}

Rigorous control of the speed with less energy consumption is always desirable in modern industries. Almost in every industry, adjustable speed drives (ASD) is extensively used to achieve such operation. [1] According to the application requirement, ASD is used to vary the speed of the motor, which results in preserving energy and revenue. Different types of faults, starting of heavy induction motors and fast releasing of breakers are the causes of sags. For general electricity utilization elements, voltage sag is not harmful. But the operation of the ASD is easily affected due to voltage sag because it consists of power electronic elements which are very sensitive to small variation in the voltage. In power system, $68 \%$ of the power quality issues occurred due to voltage sag. [2] Even due to fault at the remote area, voltage sag can also occur in a system. For ASD, severe voltage sag is considered for the drop of $10 \%$ in the rated voltage. [3] A small variation in speed of the motor may trip the ASD operation and the end product of industry suffers because of tripping of ASD. This is more often in a continuous process operation like textile mill. The first effect of sag on the performance of ASD is decreased in the DC-link voltage due to drop in source voltage amplitude. Generally, ASD is implemented with DC-link under voltage protection and the drop in DC-link voltage below to its threshold value leads to trip of ASD.

In continuous process industries, a trip of ASD causes a loss in revenue. Moreover, voltage sag affects consumers for 20-30 times in a year which leads to the loss of revenue. Typically each industry is affected with U. S. \$ 50,000 per year. [4] This paper focused on the impact of sag on ASD parameters performance. Different types of sags are presented in this paper. Using MATLAB/SIMULINK software, unsymmetrical sag, symmetrical sag and sag with phase angle shift are simulated and their impact on DC-link voltage, stator current, motor torque and speed are presented in this paper.

Materials and Methods

Adjustable Speed Drive

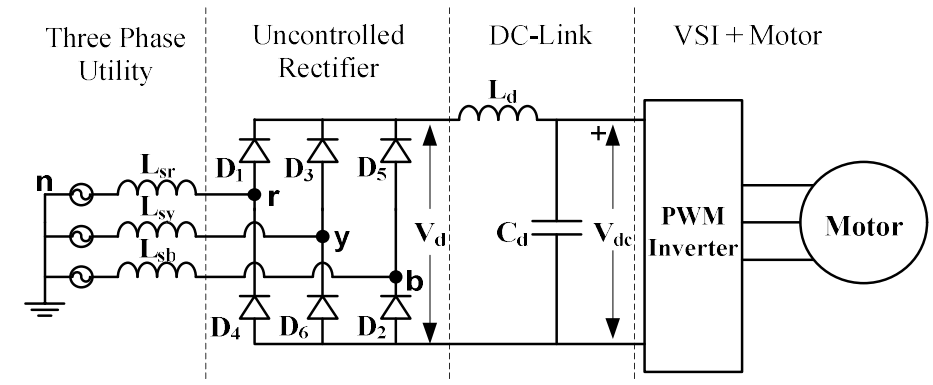

Fig. 1: Typical Circuit Diagram of ASD 


\begin{tabular}{|c|c|c|c|}
\hline \multirow{2}{*}{ 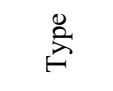 } & Symmetrical Sag & Unsymmetrical Sag & Sag with Phase Angle Shift \\
\hline & A & B & $\mathrm{F}$ \\
\hline 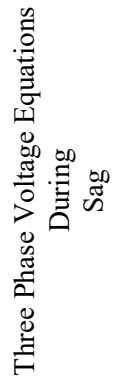 & $\begin{array}{c}\overline{V_{R N}}=V_{S a g} \\
\overline{V_{Y N}}=-\frac{1}{2} V_{s a g}-j \frac{\sqrt{3}}{2} V_{s a g} \\
\overline{V_{B N}}=-\frac{1}{2} V_{\text {Sag }}+j \frac{\sqrt{3}}{2} V_{S a g}\end{array}$ & $\begin{array}{c}\overline{V_{R N}}=V_{I a g} \\
\overline{V_{Y N}}=-\frac{1}{2} V-j \frac{\sqrt{3}}{2} V \\
\overline{V_{B N}}=-\frac{1}{2} V+j \frac{\sqrt{3}}{2} V\end{array}$ & 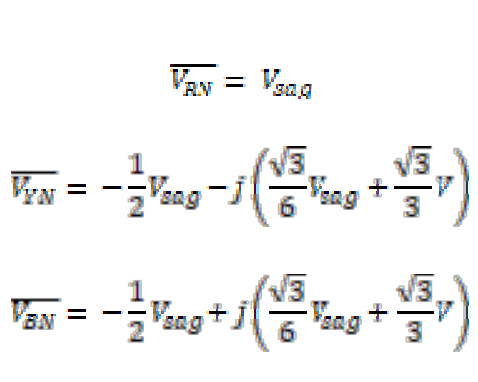 \\
\hline 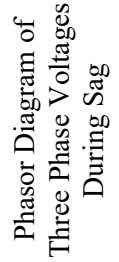 & $\begin{array}{l}\mathrm{V}_{\mathrm{BN}} \\
\mathrm{V}_{\mathrm{YN}}\end{array}$ & & $\underbrace{\vec{V}_{\mathrm{V} N}}_{V_{\mathrm{RN}}} \rightarrow$ \\
\hline
\end{tabular}

Table 1: Voltage Sag Types

In Fig. 1, a circuit diagram of typical ASD is presented. It consists of uncontrolled diode bridge rectifier $\left(\mathrm{D}_{1}\right.$ $\left.\mathrm{D}_{6}\right)$, DC-link filter circuit $\left(\mathrm{L}_{\mathrm{d}}\right.$ and $\left.\mathrm{C}_{\mathrm{d}}\right)$ to remove ripples in DC-link voltage and current, and three phase inverter with a microcontroller to drive it. Precise control of motor speed is achieved by using pulse width modulation technique in inverter. For controlled rectifier fed ASD, driver circuitry of rectifier receives signals from the controller. ASD is also classified based on speed control techniques like V/F, direct torque and field-oriented control technique for induction motor. In this paper, a V/F control technique is used.

\section{Types of Voltage Sag}

Types of voltage sag are classified based on the drop in the magnitude and shift in the phase angle of the three phase voltages. The variation in magnitude and phase angle shift depends on load connection i.e. star or delta connected load, types of faults i.e. LG, LLG, LLLG, etc. and type of transformer connection i.e. Dy, Dd, YgYg, etc. Seven types of sags are A, B, C, D, E, F and G. Most severe voltage sag is caused due to symmetrical faults like LLL or LLLG fault. This fault causes a sag of a higher magnitude. While, LG, LL and LLG faults also cause voltage sag with less variation in magnitude. [5] Apart from faults, starting of large rating motors is also a cause of voltage sag. Type A voltage sag is the most severe sag among all, which is caused by symmetrical faults. Type B and type E are unsymmetrical sags. Whereas, type C, type D, type F and type $G$ are sag with phase angle shift. [6] For three types of voltage sag, phasor diagrams and phase voltage equations during sag are presented in Table-1. The pre-event healthy operating per phase voltage is ' $\mathrm{V}$ '. Dotted lines are the three phase voltages during normal conditions and dark lines are the phases during sag event.

\section{Simulation Study}

Using MATLAB software, the simulation is carried out to study ASD performance under a different type of voltage sags. V/F control technique drived squirrel cage induction motor based ASD is used in the simulation. The simulation model is shown in Fig. 2, where the total impedance of source and line is $1+\mathrm{j} 0.03142 \Omega$ and ASD parameters used in the simulation are given in Table-2. Simulation is carried out for $0.5 \mathrm{~s}$. The loading effects and starting transients of ASD are up to $0.2 \mathrm{~s}$. Sag is created in the simulation model for $0.1 \mathrm{~s}$ between $0.3 \mathrm{~s}$ to $0.4 \mathrm{~s}$, by short circuit faults with ground and fault resistance $0.001 \Omega$ and $1.1 \Omega$ respectively.

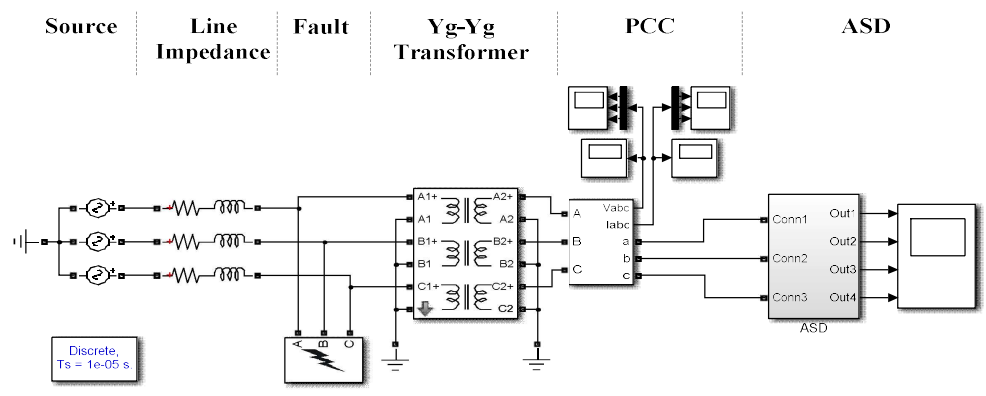

Fig. 2 : Simulation Model of ASD with Voltage Sag Arrangement. 


\begin{tabular}{|c|l|c|}
\hline Sr. No. & \multicolumn{1}{|c|}{ Parameter } & Rating \\
\hline 1 & Rated power of the motor & $2200 \mathrm{~W}$ \\
\hline 2 & Mutual inductance & $275 \mathrm{mH}$ \\
\hline 3 & Stator leakage inductance & $10.6 \mathrm{mH}$ \\
\hline 4 & Stator voltage per phase & $230 \mathrm{~V}$ \\
\hline 5 & Stator resistance per phase & $2.8 \Omega$ \\
\hline 6 & Inertia of the motor & $0.0184 \mathrm{kgm} 2$ \\
\hline 7 & Rotor leakage inductance & $10.7 \mathrm{mH}$ \\
\hline 8 & Rotor resistance per phase & $2.1 \Omega$ \\
\hline 9 & Rated Speed of the motor & $2830 \mathrm{rpm}$ \\
\hline 10 & Inductor of DC-link & $1.56 \mathrm{mH}$ \\
\hline 11 & Capacitor of DC-link & $200 \mu \mathrm{F}$ \\
\hline
\end{tabular}

\section{Table 2: Simulation Parameters}

During type B, type F and type A sags, the point of common coupling (PCC) three phase voltages are shown in Fig. 3. While the variation in the DC-link voltage during type B, type F and type A sags are presented in Fig. 4(a). DC-link capacitor rating is important to sustain the drop in the DC-link voltage. Drop in the DC-link voltage will be less for a high value of DC-link capacitor and vice versa. Due to operation of three phase rectifier as single phase rectifier, more variation in DC-link voltage is observed for type B and type F voltage sag. [7]

Fig. 4(b) shows the waveform of the motor stator current during different types of voltage sags. Due to the fall in DC-link voltage, motor stator voltage also drop down which leads to a drop in the current of stator. For type A sag, drop in stator current is more and least in type B voltage sag. An equilibrium condition is attained by the motor if the load torque equals to electromagnetic torque. Hence, the stator current is increased suddenly to maintain load torque equals to electromagnetic torque to acquire an equilibrium condition. Even, at the point on wave of sag recovery, motor will draw more current due to fall of motor speed during voltage sag. If the motor is installed with overcurrent protection then tripping of ASD will occur at the point on wave of sag recovery.

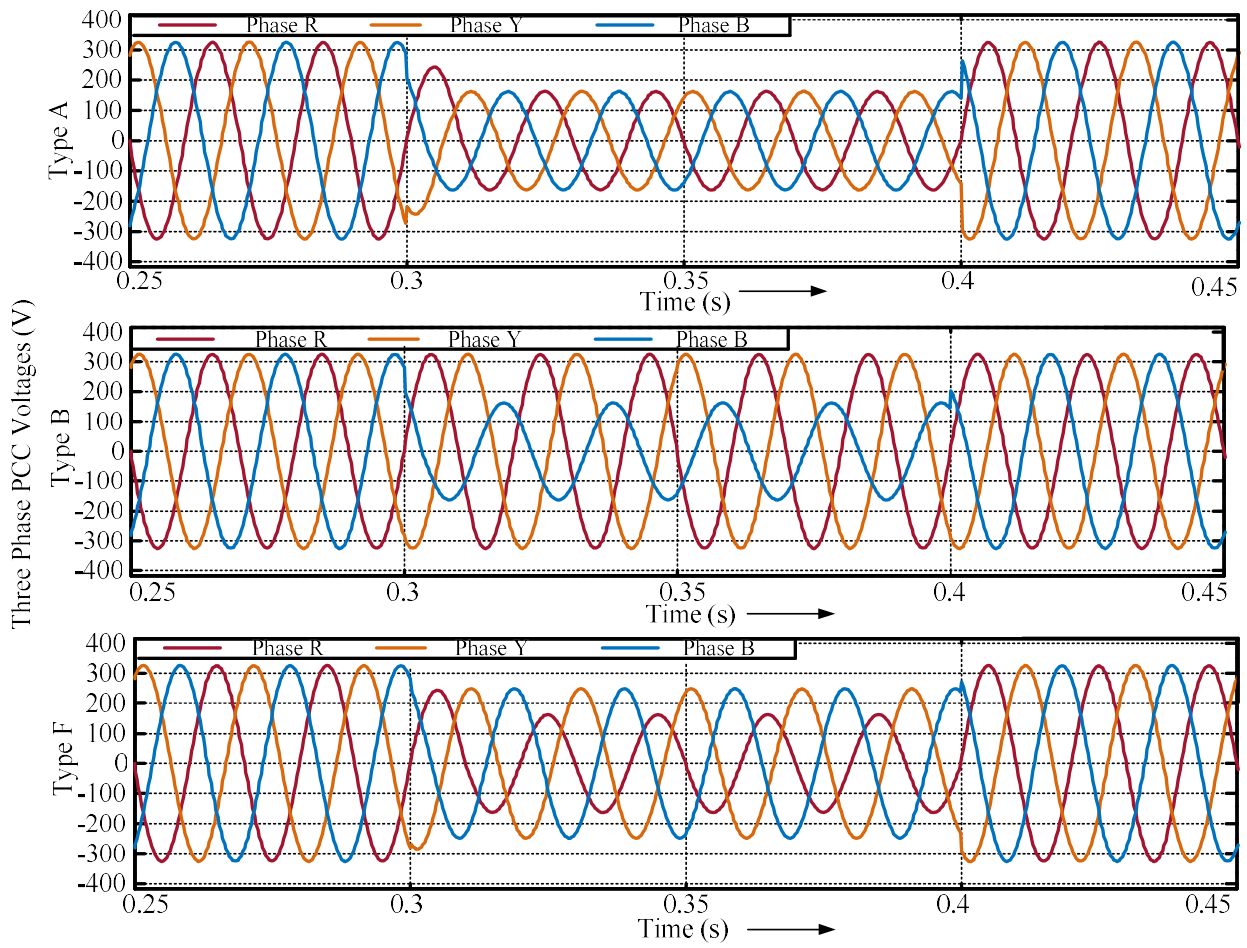

Fig. 3: ASD Terminal Voltages during Various Types of Voltage Sag. 


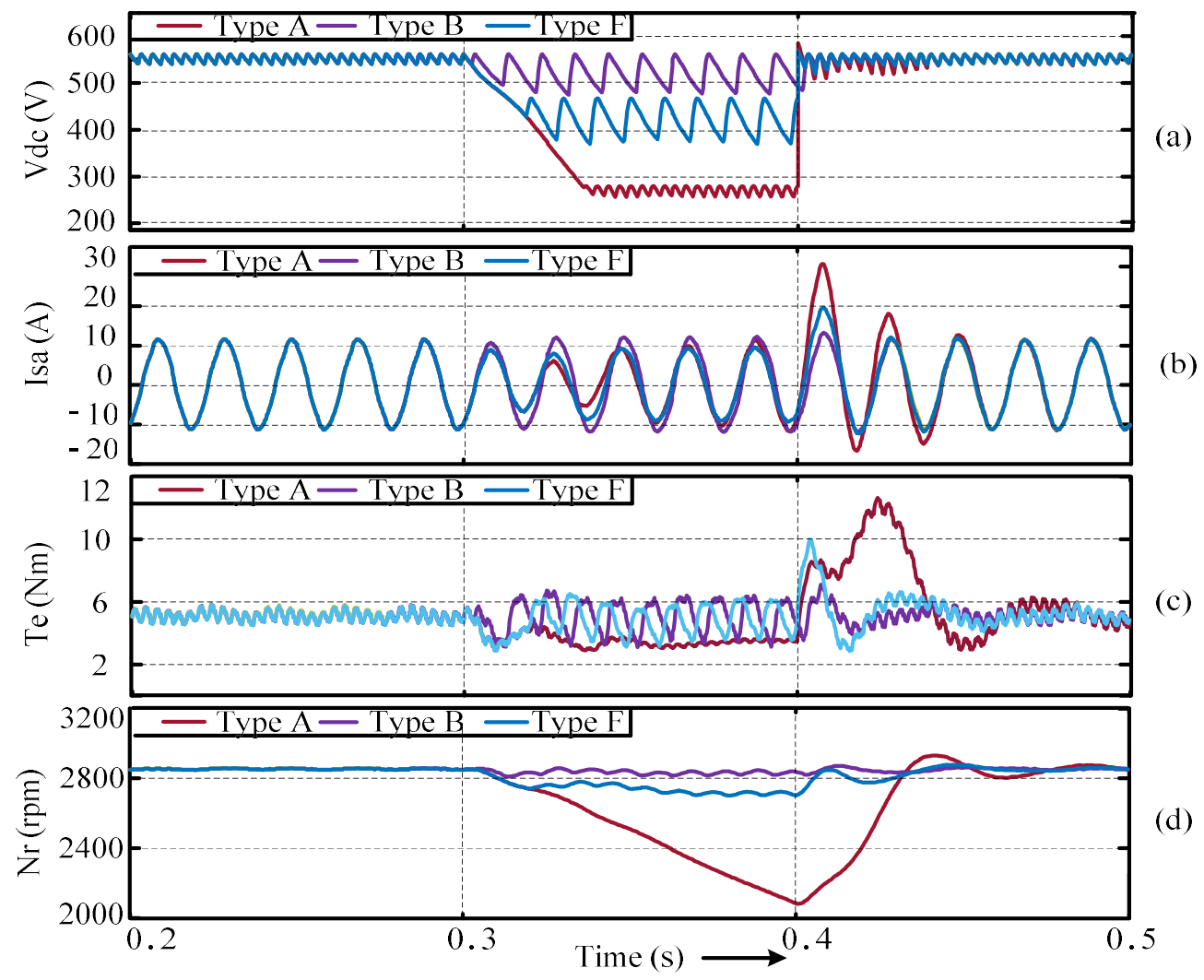

Fig. 4: Performance of ASD during Various Types of Voltage Sag, (a) DC-Link Voltage, (b) Stator Current, (c) Electromagnetic Torque (d) Speed of the Motor

The torque of the induction motor is directly proportional to the square of the stator voltage. Hence, during type A sag, torque drops down drastically due to drop in the three phase voltages. Furthermore, during unsymmetrical voltage sag, negative sequence current is drawn by the motor. This negative sequence current established its own negative sequence torque with the existing positive sequence torque, which results in oscillation of the net motor torque [8], as depicted in Fig. 4(c) for type F and type B sags.

The variation in speed for more than $\pm 10 \%$ will result in a trip of ASD. As the load torque is constant, a drop in motor electromagnetic torque results in a fall of motor speed to satisfy the equilibrium condition. Hence, a drop in speed of the motor for type A sag is more compare to type F sag and it is least for type B voltage sag as depicted from Fig. 4(d).

\section{Results and Discussion}

From the simulation results, it is observed that due to operation of three phase rectifier as single phase rectifier, more oscillation in DC-link voltage is observed for type B and type F voltage sag. However, during type A voltage sag, oscillations in DC-link voltage is less, as all the three phase voltages fall equally. For type A sag, drop in stator current is more and least in type B voltage sag. At point on wave of sag recovery, the motor will draw huge current due to sudden increase in stator voltage. Similarly, the motor torque rises sharply due to recovery of stator voltages at point on wave of sag recovery. A drop in motor electromagnetic torque results in a fall of motor speed to satisfy the equilibrium condition. Hence, a drop in speed of the motor for type A sag is more compare to type F sag and it is least for type B voltage sag.

\section{Conclusion}

The impact of various types of sag on ASD is studied in this paper. The first impact of voltage sag observed on ASD is the drop in the DC-link voltage. From the simulation results, transient currents at the point on wave of sag recovery and pulsating nature of torque during unsymmetrical voltage sag are some major effects observed on ASD. Drop in the DC-link voltage indirectly causes drop in speed which may trip ASD used in continuous process operation. Hence, whole process gets affected and results revenue lost. These effects depend on the sag magnitude, sag duration and type of sag occurred at PCC. From the simulation results, most severe effects on ASD parameters performance are observed during type A sag, among all types of voltage sags. 


\section{References}

1. Navita Khatri, Ankita Jain, Vinod Kumar and R. R Joshi, "Voltage Sag Assessment with Respect to Sensitivity of Adjustable Speed Drives in Distributed Generation Environment," IEEE International Conference on Computer, Communication and Control, pp. 1-6, Sept. 2015.

2. Suma Jothibasu and Mahesh K. Mishra, "A Control Scheme for Storageless DVR Based on Characterization of Voltage Sags," IEEE Transactions on Power Delivery, Vol. 29, No. 5, pp. 2261 - 2269, 2014.

3. J. L. Duran-Gomez, P. N. Enjeti and Byeong Ok Woo, "Effect of Voltage Sags on Adjustable-Speed Drives: A Critical Evaluation and an Approach to Improve Performance," IEEE Transactions on Industry Applications, Vol. 35, No. 6, pp. 1440 - 1449, Dec. 1999.

4. Suma Jothibasu and Mahesh K. Mishra, "An Improved Direct AC-AC Converter for Voltage Sag Mitigation,” IEEE Transactions on Industrial Electronics, Vol. 29, No. 62, pp. 21 - 29, Jan. 2015.

5. M. H. Bollen, "Understanding power quality problems," IEEE press, vol. 3, New York, 2000.

6. Milutin P. Petronijevi, Nebojša Mitrovi, Borislav Jefteni and Vojkan Kosti "Effects of unsymmetrical voltage sags on adjustable speed drives torque ripple," 35th Annual Conference of IEEE Industrial Electronics, pp. 1128 - 1133, Nov. 2009.

7. Anurag Khergade, R. J. Satputaley, Shivam Garg and Sanghratna Tembhekar, "Analysis of Different Types of Voltage Sag and Its Effects on Adjustable Speed Drive," presented at IEEE International Conference on Power Electronics, Drive and Energy Systems Conference, Madras, India, Dec. 2018.

8. Vijaya Huchche, Nita Ravindra Patne and Anjali Junghare, "Computation of Energy Loss in An Induction Motor during UnsymmetricalVoltage Sags-A Graphical Method," IEEE Transactions on Industrial Informatics, Vol. 14, pp. 2023-2030, May 2018. 